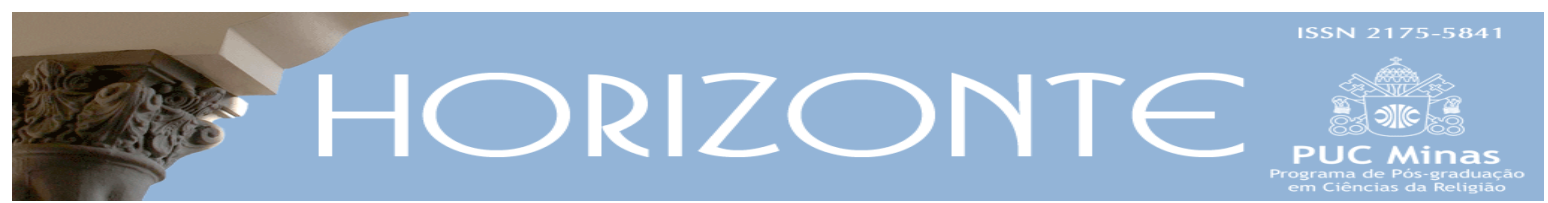

Dossiê: Ordens Religiosas Medievais: Poder e Sociedade - Artigo Original (c) (i)

DOI - 10.5752/P.2175-5841.2017v15n48p1274

\title{
O Santo e a Cidade: a pregação urbana de Santo António nos Sermões Medievais
}

\author{
The saint and the city. \\ Saint Anthony's urban preaching in Medieval sermons*
}

Eleonora Lombardo *

\begin{abstract}
Resumo
Este artigo intenta apresentar como a pregação de Santo António de Pádua está conectada com a cidade. Através de alguns exemplos tomados das legendas hagiográficas e sermões, o autor reconstrói as mudanças de atitudes de hagiógrafos e pregadores ligados a António algumas vezes a um contexto urbano geral e, em última medida, a cidade de Pádua. Em particular, o artigo se detém sobre alguns textos que destacam o efeito da pregação de Santo António no seu público-alvo, ou seja, a população da cidade em que falava. 0 período da análise é primariamente compreendido durante a canonização do santo, em meados do século XIV. Apesar disso, algumas referências a autores da época posterior serão feitas como comparação e aprofundamento da panorâmica oferecida. No final da Idade Média, santo António acabaria por ser, em certa medida, o modelo para os frades mendicantes, talvez atraídos pelos santos mais próximos no tempo.
\end{abstract}

Palavras Chave: Santo António; Pádua; Cidade; Pregação; Sermões Medievais.

\begin{abstract}
The article is intended to present how saint Anthony of Padua's preaching is connected with the city. Through some examples taken from hagiographical legends and sermons, the author reconstructs the changing attitudes of hagiographers and preachers linking Anthony sometimes to a general urban context and, later in time, to the city of Padua. In particular, the article focuses on some texts that highlight the effect of the preaching of Saint Anthony on his target audience, that is, the population of the city in which he spoke. The period of analysis is primarily understood during the saint's canonization in the midfourteenth century. Despite this, some references to authors of the later period will be made as a comparison and deepening of the panorama offered. At the end of the Middle Ages, Saint Anthony would eventually be, to some extent, the model for the mendicant friars, perhaps attracted by the saints closest in time.
\end{abstract}

Key-Words: Saint Anthony; Padua; City; Preaching; Medieval Sermons.

Artigo submetido em 26 de agosto de 2017 e aprovado em 30 de dezembro de 2017.

* O artigo apresentado é parte de um projeto de pós-doutoramento financiado pela Fundação para Ciência e Tecnologia de Portugal (SFRH/BPD/70408/2010). A Autriz está investigadora integrada do Instituto de Filosofia da Universidade do Porto (Faculdade de Letras da Universidade do Porto, Via Panorâmica s/n, 4150-564 Porto, Portugal) e do Instituto de Estudos Medievais da Faculdade de Ciências Sociais e Humanas da Universidade Nova de Lisboa. O título do projeto é: "Sermons on Saint Anthony of Lisbon: between hagiography and orality (about 1232-1350)".

\footnotetext{
* Doutora em História (Universidade de Padova), atualmente faz pós-doutorado no Inst. de Filosofia da Fac. de Letras da Univ. do Porto e no Centro de Invest. Transdisciplinar Cultura Espaço e Memoria Gabinete de Filosofia Medieval (Univ. do Porto), Portugal. País de origem: Portugal. E-mail: elombardo@letras.up.pt
}

Horizonte, Belo Horizonte, v. 15, n. 48, p. 1274-1298, out./dez. 2017 - ISSN 2175-5841 


\section{Introdução}

Desde o início de seu culto, a figura de Santo António de Pádua foi marcada pela eficácia da sua pregação e a sua capacidade de converter e mover as pessoas. $\mathrm{O}$ objetivo deste artigo é fornecer uma visão geral sobre a pregação de Santo António na cidade, como pode ser observado nas lendas hagiográficas e nos sermões que lhe foram dedicados na Idade Média. Em particular, vou me concentrar sobre alguns textos que destacam o efeito da pregação de Santo António no seu público-alvo, ou seja, a população da cidade em que falava. O período da análise é primariamente compreendido durante a canonização do santo, em meados do século XIV. Apesar disso, algumas referências a autores da época posterior serão feitas como comparação e aprofundamento da panorâmica oferecida. O que vou fazer é, portanto, procurar responder as perguntas seguintes:

- Qual foi a atitude dos escritores sagrados e dos pregadores que lembraram a campanha de pregação em Pádua, ou pelo menos numa cidade, de António?

- Qual foi o seu papel na divulgação e afirmação da devoção ao santo português?

- A memória deste episódio foi um tema central da homilética sobre o santo ou se dissolveu dentro das questões e exaltações mais gerais?

\section{António pregador e santo na hagiografia dos séculos XIII e XIV}

Desde 01 de junho de 1232, a data de preparação da bula de canonização de António, a glória da sua pregação tornou-se um dos centros da sua santidade ${ }^{1}$. Esta é celebrada também através das palavras do Evangelho Segundo Marcos (16, 30): Illi autem profecti predicaverunt ubique, Domino cooperante et sermonem confirmante sequentibus signis que foram utilizadas na bula de canonização para

\footnotetext{
${ }^{1}$ A canonização foi primeramente anunciada pela bula "Literas quas" do dia 1 Junho 1232, redigida pelo papa Gregorio IX em Spoleto [Bullarium Franciscanum = BF, 1, p. 79], e depois oficialmente confirmada pelo mesmo papa, no dia 23 Junho do mesmo ano, pela bula Cum dicat Dominus (BF, 1, p. 79-81). (Cfr. PACIOCCO, 2006, p. 70, 259; ACROCCA, 2014).
} 
falar dos seus méritos durante a vida e garantidos para os seus milagres ${ }^{2}$. Toda a vida de António, ou melhor, os seus méritos, que não foram particularmente tratados na bula, identificara-o com a sua pregação. O dossiê da inquisitio realizado pelo Bispo de Pádua, Jacopo Corrado, pelo Prior de São Bento Giordano Forzaté e pelo frade e pregador Giovanni, prior de Santo Agostinho, não chegou até hoje3. Historiadores especialistas de santo António julgam bastante seguro que parte dela é mesclada, devidamente remodelada, na primeira hagiografia dedicada ao santo, a Assídua, elaborada na misma altura da proclamação solene da canonização [Gamboso (1981, p. 52-54); Paciocco (1990) e Tilatti (1997, p. 48) dizem-se contrários a esta hipótese].

Nesta vida, os momentos nos quais a santidade de António encontra a sua manifestação mais perfeita são essencialmente três: o sermão diante dos dominicanos de Forli - ou seja, o momento da revelação da sua vocação - a campanha de pregação para a Quaresma de 1231 - o apogeu - e os milagres - a confirmação [Assidua, 1981 (STRAPPAZZON, 2014), cap. 8, 4-9, p. 314-316 (248-249); cap. 11, 57, p. 332-334 (251) e cap. 13, p. 338-346 (252-253); cap. 31-47, p. 440-505 (274290).]4. Se não é surpreendente a forte predileção do hagiógrafo em favor de Pádua, é importante notar os termos usados para a pregação na cidade do santo [TILATTI, 1997, p. 62-68. Em geral cfr. PACIOCCO, 2006, p. 191-198].

Desde a sua primeira campanha de pregação em Emilia, o santo está citando os evangelistas [Assidua, 1981 (STRAPPAZZON, 2014), cap. 9, 3, p.319 (248)], enquanto na frente da Cúria Romana é sermo sale gratia conditus [Assidua, 1981 (STRAPPAZZON, 2014), cap. 10, 3, p. 324 (250), esta é uma citação de Colossenses

\footnotetext{
2 “ [...] ad hoc tamen ut sanctus habeatur apud homines in Ecclesia militante, duos sunt necessaria; virtus morum et veritas signorum, merita videlicet et miracula. Ut hec et illa sibi invicem contestentur, cum nec merita sine miraculis, nec miracula sine meritis plene sufficient ad perhibendum inter homines testimonium sanctitati; sed cum merita sane precedunt et clara succedunt miracula, certum prebeant indicium sanctitatis, ut nos ad ipsius venerationem inducant, quem Deus ex meritis precedentibus et signis subsequentibus exhibet venerandum. Que duo ex verbis Evangeliste plenius colliguntur: Illi autem profecti predicaverunt ubique, Domino cooperante et sermonem confirmante sequentibus signis". Ibid., pp. 80-81.

${ }^{3}$ Os nomes e apelidos incontram-se na misma bola Cum dicat Dominus (BF, 1, p. 80): «[...] eidem episcopo, et dilectis filiis Fratri Jordano sancti Benedicti, et Joanni sancti Augustini Prioribus Ordinis Fratrum Praedicatorum Paduanorum receptionem Testium de miraculis eiusdem Sancti duximus committendum. Nuper autem tram per relationem predictorum episcopi et priorum, quam per depositiones testium super hoc receptorum, de ipsius uirtutibus et miraculorum insigniis cretiores effecti [...]» (ibid., p. 81) cfr. PAClOCCO, 1997, p. 117-127; RIGON, 2002, p. 35-37.

${ }^{4}$ Para as vidas indicam-se os capitulos e as paginas conforme a edição critica editada para Gamboso, em parêntese colocam-se as referências a tradução italiana do 2014 no volume editado para Dolso (2014).
} 
4, 6.] e, acima de tudo, Archa Testamenti [Assidua, 1981 (STRAPPAZZON, 2014), cap. 10, 3, p. 324 (250), esta é uma citação de Colossenses 4, 6.]. No entanto, é em Pádua que toma sua própria voz e supera as características do pregador sagrado, porque a sua pregação, a sua palavra, é um objeto de veneração em si mesmo. $\mathrm{O}$ longo capítulo dedicado à devoção dos cidadãos de Pádua e ao fruto da pregação do santo [Assidua, 1981 (STRAPPAZZON, 2014), cap. 13, p. 338-346 (252-253).], traz uma drástica mudança no assunto. António é o centro de um movimento de massas que é descrito com palavras fervorosas. Saído das igrejas da cidade, leva consigo uma população diversificada, cuja presença, na economia narrativa da lenda, se torna mais importante referir do que as próprias palavras do pregador. Ficamos assim informados, antes de mais, sobre os efeitos de sua pregação, enquanto os conteúdos são descurados. Mesmo quando António volta a envolver-se ativamente, no capítulo, torna-se uma pessoa cujas palavras foram capazes de mudar a estrutura da cidade:

\begin{abstract}
"Conduziu de volta os discordantes a paz fraterna; devolveu a liberdade aos presos; voltou o que havia sido sequestrado por desgaste ou violência: veio para o ponto em que, hipotecadas casas e terras, colocaram o preço aos pés do santo. Com base no parecer dele, o que era removido bem ou mal foi devolvido aos roubados. Prostitutas foram libertadas do seu mercado sujo e os ladrões famosos por crimes abstém-se de tocar nas coisas dos outros. [...] Eu não posso deixar passar em silêncio enquanto ele induziu tão grande multidão de homens e mulheres a confessar seus pecados, para que não eram suficientes para ouvi-los nem os frades nem os outros sacerdotes, que o acompanharam no grande terraço" [Assidua, 1981 (STRAPPAZZON, 2014), cap. 13, 11-13, p. 344-346 (253).].
\end{abstract}

Sem pretender insistir no papel da pregação do santo, especialmente em Pádua, nas legendas citadas, acho que é útil definir alguns outros pontos que permitem enquadrar melhor a relação entre a hagiografia e os sermões para sua festa (LOMBARDO, 2016). Apesar que a Assidua não experimentou uma distribuição especial fora da cidade de Pádua, onde permaneceu por um longo tempo o texto lido durante a liturgia de 13 de Junho, ela foi a base para todas as vidas subsequentes, as quais enriqueceram ou reinterpretaram os dados fornecidos pelo primeiro hagiógrafo anônimo. Por isso, é de particular interesse ver o papel da pregação no texto litúrgico usado pelos frades da Ordem, já nos anos 40 do século XIII. Ou seja, 
como um outro hagiógrafo, que foi um frade, mas não em Pádua, interpretou e depois espalhou a ideia da centralidade da oratória na vida e na afirmação da santidade do António (GAMBOSO, 1985, p. 11-33; DOLSO, 2014, p. 297-300. GIULIANO DA SPIRA, 1985).

Juliano de Speyer, no Officio Rítmico e na Vita Secunda, ainda mais enfatiza a centralidade da pregação na experiência de António, aumentando os episódios mencionados e, especialmente, os efeitos benéficos que tinham sobre as pessoas que ouviam as palavras do futuro santo. Manifesta a sua grandeza em todos os lugares nos quais se encontrava falando: intimidados "certas personagens altamente colocadas e dignas de repreensão", ofereceu a todos os ouvintes "o ensino que melhor convier-lhes" [GIULIANO DA SPIRA, 1985, cap. 4, 17, p. 412 (306), cap. 5, 2, p. 416 (307).]. Na Vita secunda, também os pontos apicais da experiência de António aumentaram com a introdução do episódio do milagre de Arles, cuja intenção não era tanto para enfatizar as habilidades de oratória do frade, quanto para afirmar a continuidade com a fundação da Ordem. Durante esta celebração da palavra do Santo [GIULIANO DA SPIRA, 1985, cap. 5, 10-12, pp. 420-422 (307-308).], no decorrer de sua ação em todas as cidades e castelos, nas igrejas e nas praças, a centralidade de Pádua está parcialmente perdida. Em parte, porque, para Juliano de Speyer, ainda é um dos destaques do evento da vocação de santidade de António graças à recuperação literal das palavras da Assidua sobre os efeitos benéficos para a cidadania [Assidua, 1981, cap. 13, pp. 338-346 (252-253); GIULIANO DA SPIRA, 1985, cap. 7, pp. 428-432 (309-310).]. Em parte, porque assistimos a uma decontextualização dos atributos de sua pregação. Por exemplo, se a Assídua informa que foi elogiado pelos sábios de Roma, Juliano de Speyer tem silêncio sobre o lugar em que foi apreciado por eles, ainda que seja lembrada a devoção do bispo e do clero de Pádua [Assidua, 1981, cap. 10, p. 320-324 (250) e cap. 13, 6, p.340 (252); GIULIANO DA SPIRA, 1985, cap. 5, 3-4, p. 416-418 (307) e cap. 7, 3, p. 428 (309).]. Nem mesmo deixa um vislumbre sobre a área de governo do tirano, e reduz a uma breve menção também os efeitos da sua pregação anti-herética em Rimini [GIULIANO DA SPIRA, 1985, cap. 5, 6, p. 418 (307).]. 
Em outra ocasião, mostrei que, a partir da Assidua, assistimos a uma espécie de de-contextualização ou melhor de universalização do seu culto. Santo António de Pádua passa a ser Santo António da Ordem dos Frades Menores para voltar a Pádua no século XV (LOMBARDO, 2014, p. 237-241). O caminho percorrido por Juliano de Speyer melhora nas vidas sucessivas, que, apesar de ser quase todas escritas em Pádua, não conseguem circunscrever a ação benéfica do santo ao ar da cidade do rio de Pádua, o Brenta. Só, no início do século XIV, um outro frade tentou deslocar os lugares do culto a António numa outra cidade, Limoges. Na intenção de Jean Rigauld, autor de uma lenda hagiográfica conhecida com o apelativo de Rigaldina, o efeito benéfico da pregação e da atividade do santo seria implantado ali de forma equivalente ao que aconteceu em Pádua (GAMBOSO, 1992, p. 333-366; CAROZZI, 1997). Pode-se dizer que a sua intenção é que Limoges seja o lugar da santidade na vida, e Pádua da santidade na morte.

Esta tendência a universalização é particularmente sentida pelos pregadores que estavam falando sobre António. Como foram chamados a falar, ou melhor escrever, por seus confrades e ensinar-lhes o que dizer sobre um santo que foi levantado como um modelo do pregador para toda a Ordem, demoraram muito tempo da sua pregação sobre as virtudes e a maneira pela qual foi conduzida5. Mais raramente, no entanto, pararam sobre os efeitos dela ou do contexto em que foi exercida. Então, a menção da cidade de Pádua é mesmo mais ocasional e ligada a contextos puramente locais. Nos inúmeros sermões dedicados ao santo Português na Idade Média, o tema da pregação é central. É, de fato, o modelo por excelência do pregador para os Frades Menores, também graças a uma maleabilidade, primeiro hagiográfica, e depois homilética, ausente em outros santos, como São Francisco e São Luís de Anjou (BOUGEROL, 1983; HOROWSKI, 2013; STANISLAO DA CAMPAGNOLA 1971; DELMAS, 2015). Os percursos das duas fontes cruzam-se

\footnotetext{
${ }^{5}$ Estamos a falar de mais que 223 sermoes entre a canonizaçao e a medade do século XIV. A maioria foi escrita na Italia e na França, mas hà outros em todas a Europa. cfr. Lombardo (2012, p. 16-24). Nesta fase de estudo não està possivel ligar os sermões às festas dedicadas ao santo, sobre tudo nos séculos a seguir. Ao contrário, os textos analizados por esta altura, parecem ligados à formação da identidade dos frades minores e dos bons pregadores. São poucos os casos de sermões que poderiam ser pronunciados ou escritos em perspectiva de um auditorio popular. Sò desde o final da Idade Media, com os pregadores da Observancia franciscana, a ligação entre a devoção popular e a pregação como reportada nos textos homíleticos começam ficar mais clara.
} 
inextricavelmente desde os anos 40 do século XIII, como evidenciado pelos famosos sermões de João de la Rochelle (BALDUINUS AB AMSTERDAM 1958, p. 44-58), de modo que, no caso da Rigaldina, é difícil de entender se era a fonte para uma pregação centrada principalmente no pauperismo e numa determinada interpretação da pregação de uma forma mais popular, ou se tiver sido, em grande parte influenciada pelos sermões em voga na época. Duas dentre as linha principais de interpretação permanecem por um tempo longo entre aquelas caracterizam a imagem de Santo António: a primeira diz respeito à aceitação da vida como frade menor, e a segunda diz respeito a virtude da sua sabedoria. No entanto, ambas sofrem de alguns deslizamentos ao longo do tempo. Assim, António entrou na Ordem dos Frades Menores, em primeiro lugar, pela vontade de martírio, como testemunha, por exemplo, Corrado Holtnicker da Saxônia (Um primeira edição dos sermões foi publicada para GAMBOSO, 1974, p. 80-87), em seguida, pela vontade de ser pobre, de acordo com muitos sermões das últimas décadas do século XIII e quase todos os da primeira metade do décimo quarto - basta mencionar os dois casos famosos de Lucas Leitor e Mateus de Aquasparta - e, finalmente, para a sua plena aceitação da regra (isto é, num grupo de reelaborações de um famoso sermão conhecido como o Iste pauper) (LOMBARDO, 2014). Há muito tempo que tive a oportunidade de falar em detalhe em vários locais sobre a segunda linha de interpretação, que vê um entrelaçamento de conhecimento bíblico, ensino e pregação, com uma prevalência de uma ou de outra, dependendo da localização e da idade do autor do texto (LOMBARDO, 2012; LOMBARDO, 2015). A partir, principalmente do final do século XIII, estas duas linhas de interpretação foram acompanhadas por uma forte interpretação do santo centrada sobre o pauperismo que o viu como amostra da pobreza franciscana, de acordo com o exemplo de Francisco e, em alguns casos, do próprio Cristo. À luz desta informação preliminar, não parece-me exagerado dizer, de acordo com Maria Teresa Dolso, que o caso do estudo da hagiografia e da homilética sobre santo António pode levantar o véu do que tem sido o estudo da aplicação do ideal franciscano fora da Itália Central, ou melhor da Úmbria [Dolso (2014, p. 8) cfr. Merlo (2014, p. 242). A expressão 
"minoritismo padano", para indicar a evolução particular do franciscanismo longe de Assis, fica em Rigon (2001, p. 21-45)].

\section{0 papel da pregação nos sermões sobre santo António (séculos XIII-XIV)}

Em particular, em relação ao material aqui proposto, os sermões permitem avaliar como os frades queriam viver o ideal franciscano em suas vidas diárias, muitas vezes muito longe daquela encarnada pelo próprio fundador. Não parece uma coincidência que os textos que tratam recuperar ou revisar as informações sobre o papel cívico do Santo são principalmente limitados a apenas a península italiana, onde a mensagem pode desfrutar de maior sucesso do que em outras áreas da Europa. O primeiro entre os cinco sermões dedicados ao santo para João de Aragão, filho do rei Jaîme II de Aragão, arcebispo de Toledo e provavelmente terciário da ordem franciscana (morreu em 1334), é uma importante exceção a esta regra [Sobre João de Aragão e Anjou: Avezou (1930); Lambert (1924); Villapadierna (1977, p. 162163). Os sermões estão catalogados em Schneyer (1969 - 1974: vol. 3, 1971, p. 619) e ficam conservados no manuscrito Valencia, Arquivo de la Catedral, ms. 182, ff. 168vb - 171va.]. Tem o thema: In gutture tuo sit tuba quasi aquila super domum Domini (Os. 8, 1). A estrutura do sermão é muito semelhante aos outros sermões sobre a sabedoria $^{6}$. Em particular, há um dos dois que chamo sermões tipológicos, o Neptalim cervus amissus (um sermão de origem francesa da segunda metade do século XIII, muito copiado e distribuído em duas grandes mudanças e algumas menores na França e na Inglaterra, com algumas cópias na Itália e, claro, na Espanha), que também está incluído na coleção na sua versão curta. No Neptalim cervus amissus o santo é exemplo da pregação diária dentro da cidade. Ele prega de

\footnotetext{
${ }^{6}$ Valencia, Arquivo de la Catedral, ms. 182, ff. 170vb-171rb]: In gutture tuo sit tuba quasi aquila super domum Domini. Ose. VIII (8, 1). Prothema. Clama necesses quasi tuba exaltat uocem tuam etc. Is. LVIII $(58,1)$. Quatuor sunt status hominum in ecclesia: quidam male uiuunt et male docent et isti sunt perfecte mali; quidam male uiunt sed bene docent et isti sunt minus mali, quidam bene uiuunt et bene docent et isti perfecte boni quia teste saluatore qui fecerit et docuerit etc. De istis fuit pater noster Anthonius sicut uerba proposita manifestant. Recurre supra ad diuisionem. Tria de beatissimo Christi confessore Anthonio describuntur, uidelicet eius: predicatio fructuosa; conuersatio gratiosa; exaltatio gloriosa [Expl.] De quarto loel II $(2,1)$ : Canite tuba in Sion, conturbentur omnes habitatores terre quia uenit dies Domini. Prope est dies tenebrarum et caliginis dies nubis et turbinis.
} 
forma rápida, ou seja, sem ceder em torpor, sem parar muito num lugar, e sem queixar-se dum trabalho que não gostava. Então, pregou um espírito de obediência, porque não tentou a tarefa do pregador, mas o aceitou quando recebido. Era liberal, ou seja, não aceitou qualquer tipo de recompensa por sua pregação. Finalmente, demonstrou repulsa a adulação que derivava de suas habilidades na oratória, de forma que foi capaz de enfrentar até mesmo o vir sanguinum que iria custar-lhe dor7. Estas três características do santo são tratadas de modo que sejam convites flagrantes a imitação para o pregador contemporâneo, chamado para sair "nas ruas e becos da cidade", e para levar a Deus "os pobres, os aleijados, os cegos e os coxos".

A diferença entre este último e o texto do príncipe de Aragão está nos efeitos não só espirituais da trombeta de Oséias, na pregação do santo, mas também na sua aplicação real, não entendida como vida da cidade, mas como vida da Igreja, como instituição que vive no interior de uma comunidade local. As três distinções clássicas da palavra "tuba" (em latin), ou seja bellatorum ad prelium animatrix, dispersorum ad convivium convocatrix, dampnatorum ad supplicium predicatrix, tem vistas aqui à função pública do anúncio da salvação, pois tuba est <...> statutorum seu legum publicatrix 8 . Aqui não pode faltar o apelo também lexical ao episódio dos estatutos de Padua em 1231, quando a campanha homilética quaresmal do santo proporcionou a inspiração de um dos capítulo dos estatutos cidadãos de Pádua em favor dos devedores insolventes [Assidua, 1981, cap. 13, 11, p. 345 (247); Giuliano Da

\footnotetext{
7 “Hoc specialiter completum fuit in beato Antonio7 qui multos et diuersos hereticos ac hristianos per predicationem suam ad Christum conuertit sicut in uita ipsius ${ }^{7}$ exprimitur manifeste. [...]

Circa secundum considerandum est quod ad hoc ut predicationis doctrina ordinata sit tripliciter debet fieri, scilicet: cum uelocitate contra pigritiam et torporem. Isa. XL (60, 8): Qui sunt isti qui ut nubes uolant?; Lc. 14 (14, 21): Exi cito in plateas et pauperes ac debiles et cecos et claudos. lustus hunc talis fuit predicatio beati Antonii unde legitur in uita sua quod predicandi auctoritate suscepta non se gratum officium sibi iniunctum exequi studuit et propter hoc in proposito uerbo ceruus dicitur. Abac. ultimo $(3,19)$ : Deus fortitudo mea et ponet $^{7}$ pedes meos quasi ceruorum; cum superioris auctoritate contra presumptuosam temeritatem, Rom. X (10, 15): Quomodo predicabunt nisi mittantur? Talis fuit predicatio beati Antonii, unde dicitur in uita sua uerbi ministerio non iniectu proprio datur, sed uocatur. Id circo additur "emissus"; cum liberalitate contra symoniacam prauitatem. Mtt. X (10, 8): Gratis accepistis gratis date; Prou. XXIII (23, 23): Noli uendere sapientiam. Talis fuit doctrina beati Antonii et quantum ad hoc adiungitur "dans"; cum prima boni operis executione. Act. I (1, 1): Cepit lesus facere et docere; Mtt. V (5, 19): Qui fecerit et docuerit magnus uocabitur in regno celorum. Talis fuit doctrina beati Antonii, sicut patet in uita sua. Eloquia pulcritudinis illa enim doctrina est pulcra que bone uite moribus adornatur. Prou. XXII (22, 17-18): Adpone fili mi cor tuum cor tuum ad doctrinam meam, que plus erit tibi, cum seruaueris eam preter eloquia pulcritudinis. [...] Prou. XXII (22, 20): Descripsi eam tripliciter in cogitationibus et scientia ut ostenderem tibi ueritatem et eloquia ueritatis. Istud habuit beatus Antonius sine omni adulatione uitia reprehendendo, unde legitur de ipso contra uirum sanguinum: clama et dolosum quod hoc genus hominum Deo sit exosum." A edição resulta da collaç̧ão dos manuscritos: Marseille, BM, 396, ff. 75vb-77vb; Oxford, Bodleian, Cant. Lit. 293, ff. 93rb-94rb; Paris, BNF, Latin 15958, ff. 274rb-275vb; Paris, BNF, Latin 16510, ff. 180va-181va ; Troyes, BM, ms 1840, ff. 129va-129v.

${ }^{8}$ Valencia, Arquivo de la Catedral, ms. 182, f. 168vb.
} 
Spira (1985, cap. 7, 9, p. 430) (309). cfr. Gasparotto (1964, p. 151-152); Gloria (1873, nr. 5511, p. 178 - 179)]. Um lembrete talvez significativo, dadas as dificuldades que o arcebispo aragonês encontrou na sua sede episcopal, onde a sua autoridade foi contestada, tanto pelo papado de João XXII quanto pelo clero e pela nobreza local que viam-no quase como um invasor, na condição de filho de um rei vizinho que tinha fortes ambições expansionistas na diocese de Toledo (AVEZOU, 1930, p. 329).

Embora a pregação fosse o foco da sua santidade, a sua configuração urbana não aparece muitas vezes nos sermões. Contudo, deve ser tomado em consideração adequada o fato que é mencionado em ambos os sermões tipológicos sobre o Santo. Como no Neptalim cervus amissus, também, algumas versões do Iste pauper insistem nisso. A preservada em um manuscrito em Paris (Paris, BNF, Lat 3735), por exemplo, usa o argumento da universalidade da pregação de António para ensinar os frades a não desistir de pregar em qualquer lugar (civitates, castella, rura) e frente a qualquer público (maiores, mediocres e minores). Ainda que talvez mostre uma preferência ligeira para os campos, onde, no final de um clímax de ascensão para redenção, o santo - e também os frades - prega o castigo e a glória para os menores9. A tarefa do pregador na cidade, no entanto, é principalmente o relato de erros e más ações, de acordo com os ensinamentos de Isaías. Lá, o pregador vai exaltare vocem suam, como para neutralizar o excesso de ruído de um lugar lotado de pessoas poderosas ${ }^{10}$.

Os sermões italianos têm outro teor. Aí, a cidade está presente e atua em níveis diferentes. O terceiro sermão do manuscrito Chig. C.V.127, por exemplo, concentrase nos efeitos da pregação de António elaborados a partir de uma lenda hagiográfica indeterminada. O frade anônimo informa que o santo tinha em si tudo o que um bom

\footnotetext{
${ }^{9}$ Sic faciebat beatus Antonius: uerbum uite frequentissime predicabat per ciuitates exaltando uocem suam maioribus, per castella predicando mediocribus, pro rura ostendendo penam et gloriam minoribus. Ecce qualiter beatus Anthonius clamauit clamore confessionis se ipsum accusando, clamore orationis continuando, clamore predicationis alios instruendo et uicia arguendo. . Ecce qualiter beatus Anthonius clamauit clamore confessionis se ipsum accusando, clamore orationis continuando, clamore predicationis alios instruendo et uicia arguendo. Dicit ergo: Iste pauper clamauit etc Paris, BNF, Latins, ms. 3735, ff. 67v-70r.

10 «Clama ne cesses quasi tuba exalta exalta uocem tuam et annuntia populo meo scelera eorum, quasi dicat: clama ne cesses redarguendo, quia Deus eternus offenditur quasi tuba tibi ostendendo quia bonum infinitum amittitur et annuncia populo meo de eorum comminando, quia eternum supplicium acquiratur» ibid.
} 
pregador precisa: a santidade da vida, a profundidade da sabedoria e a coragem de dizer a verdade quando é util. Continua, o santo censurou os príncipes, os tiranos, os soldados, os ricos, os pobres, homens e mulheres. Todos os pecadores ficaram feridos pela espada da sua pregação. Deixava claro os laços de roubo, quebrava as tentações do pecado. Graças a seus sermões, foram convertidos pecadores, usurários, patarinos. Omnes squarzabat laqueos ${ }^{11}$. A passagem é bastante longa e tem a finalidade de ajudar o leitor, certamente um outro pregador, a entender, o que teria que ser a sua função dentro do contexto da cidade em que estava a agir. Ao contrário de todas as outras passagens do sermão, o leitor é explicitamente pedido para não traduzir a citação como se não tivesse fins informativos fora do ensino para os pregadores. De acordo com o anônimo, a homilética visa a assustar os seguidores de pecados mortais, de ser fervorosa, de aconselhar-se com sabedoria, de consular com doçura, e, novamente, de não calar a verdade onde que pode ser benéfica ${ }^{12}$. Esta nota de atenção está localizada em outros sermões na coleção deste frade anônimo, provavelmente ativo no centro da Itália, nas primeiras décadas do século XIV, e que contrasta com a imagem do pregador como um baluarte da verdade contra todos os obstáculos e a qualquer custo.

Outro frade, talvez Bindo Scremi de Siena, cujo manuscrito está preservado na Biblioteca Oliveriana de Pesaro (Ms. 1300) ${ }^{13}$, afirma a necessidade de pregar a verdade, que é a doutrina da Igreja e da fé contra os hereges, apesar da cidade ser forte. A cidade parece ainda mais perigosa no sermão deste segundo frade, infestada de heresia, vícios e pecados. Para Bindo, no entanto, como para Corrado Holtnicker

\footnotetext{
11 "Ad suos predicationes conuertebantur peccatores, peccatrices, usurarii, patareni sicut ostendit legenda sua. Omnes squarzabat laqueos peccatorum gladio predicationis, sicut cantat de ipso sancta mater ecclesia. In doctrine poculis etc. Non uulgariza." Vaticano, Biblioteca Apostolica, Chig. ms. C.V.127, ff. 196rb-198va: "Vos estis lux mundi. [Mt. 5, 14] De hoc fac prothema dicens quomodo lux est alta, clara, calida sic Christus est illa lux que facit preclariorem, altum etc. in contemplatione, clarum in cognitione, calidum in affectione. [expl.] Quod nobis et uobis prestare dignetur qui uiuit et regnat etc. Amen. Fac finem.

12 «Predicare feruenter, consulere sapienter, consolari dulciter, sed numquam debet tacere ueritatem ubi ueritas potest prodesse.» ibid. ${ }^{13} \mathrm{Em}$ Bindo Scremi de Siena António è imitador dos antigos doctores da Igreja e na sua vida agiou como eles fizeram na antiguidade. Em qualquer caso, a cidade contém sempre os mismos perigos, e por isso o pregador passa do presente ao passado quando fala alternativamente da cidade e dos doutores: «Et sicut ciuitas est potens, sic ipsi fidem Christi publice predicabant contra hereticos et uitia et peccata. Hos assimilat lucerne ardenti, quia predicator debet esse lucerna ardens ut alios illuminet et inflammet quia ad hec duo debet attendere quia debet stare super candelabrum ut omnibus exempla bone prebeat quia cuius uita despicitur etc. Ideo dicitur quod fecerit et docuerit etc. Et latis merite lucerne comparatur que habuit.» Pesaro, Biblioteca Oliveriana, ms. 1300, ff. 195rb-196ra: f- 196ra. Vos estis sal terre etc. [Mt. 5, 13] Debetis scire quod ita fecit Deus de populo suo et ortolanus de planta. [expl.] curatiuam quia contra puncturam scorpionis ualet cum mille.
} 
e Servasanto de Faenza, o pregador, de que António é a imagem mais perfeita, deve ser uma luz no meio da noite e nunca esconder sua própria luz, mesmo em face do perigo $^{14}$.

Mais um outro frade, desta vez de Pádua, exprime a mesma convicção, afirmando que a tarefa do pregador é pregar a salvação e denunciar os vícios e pecados do mundo. Em seu primeiro sermão, De sancto Antonio, a relação com a cidade é perdida em favor de um discurso mais geral sobre os males do mundo, infestado por falsas promessas, falsos discursos, orgulho, falsos juízes e, finalmente,

${ }^{14}$ Corrado Holtnicker diz: « De secundo, lob. XXIX $(29,3)$ : Splendebat lucerna eius super caput meum, et ad lumen eius ambulabam in tenebris. Caput anime mens est, super quam lumine lucerne, id est predicatoris doctrina splendente in tenebris presentis miserie securius ambulamus. $\mathrm{O}$ si aliquis per pontem strictum magni fluminis ambulare deberet in tenebris quam neccessaria sibi esset lucerna! Et uere artus pons et arta uia est iusticia! Mtt. VII $(7,14)$ : Arta uia est que ducit ad uitam. Vere arta artatur, enim, a dextris per illud preceptum. Mtt. VII $(7,12)$ : Omnia quecumque uultis ut faciant uobis homines et uos facite illis. Artatur autem a sinistris per illam prohibicionem. Tob IV $(4,16)$ : Quot ab alio oderis fieri tibi. Vide tu ne aliquando alteri facias. Bernardus: "lusticia nec factura est alteri quod sibi fieri nolit. Quod sibi fieri uelit negatura». Caueas ergo, karissime, ne a dexteris uel a sinistris labaris de ponte per hanc artam uiam oportet nos transire hoc mare magnum et spatiosum, , uidelicet presens seculum. Vnde, ne propter tenebras huius uite cadamus, lucerna doctoris indigemus. Hoc bene significatum est Exo. IV , ubi legitur quod filii Israel per lumen columpne mare transierunt in tenebris nocturnis. $O$ quot super que per lucernam nostram luminosam, scilicet Antonium, periculosam huius maris uiam transierunt spiritualiter quod etiam eius meritis legimus factum corporaliter. Hic dicit quomodo sub radio lucis naufragos ad portum duxerit .» Gamboso (1974, p. 86). A presente edição està feita a partir dos manuscritos: Padova, Bibl. Antoniana, 472, ff. 30vb- 31va; Vaticano, Bibl. Apostolica Vaticana, 180, ff. 166rb-166vb; Cambridge, Caius and Gonville, 409.608, ff. 156vb-158vb; Paris, BNF, Latin 3736, ff. 185v-186v; Paris, BNF, Latin 3742, ff. 68v-69v; Troyes, BM, 1494, ff. 266vb-267rb; Munich, Staatsbibliothek, clm 16026, ff. 23ra-23va.

Servasanctus de Faentia: « Tercio, beatus Antonius habuit sapienciam prophetarum, quorum est preuidere futura et ea populis nunciare. Talis enim reuera fuit Antonius, dum per se Paduanam ciuitatem esse sublimandam preuidit, dum etiam canonico socio improperanti: "Vade, uade, quia forsitan sanctus eris", prophetice sic respondit: "Cum me sanctum audieris, Deum utique collaudabis". Lege hec attencius in Legenda, que sunt breuiter hic inserta. Vere enim beatus Antonius spiritualiter gallus fuit, cantans in die, cantans in nocte, et a diuinis laudibus et predicacione non cessans. Vnde de eo potest exponi illud lob. $38(38,36)$ : Quis posuit in uisceribus hominis sapienciam? aut quis dedit gallo intelligenciam? Magne enim sapiencie et intelligencie gallus fuit, dum ad modum galli suis cantibus egros spiritualiter confortauit, lapsos reparauit, lapsos fortificauit, et malos et impios uerbis attribuit. Nam et ad cantum galli, sicut dicit Ambrosius, egri confortantur, mucro latronis absconditur et lapsis fides reuertitur. Sed non sunt hodie tales nostri speculatores, nostri rectores, nostri maiores, quia populis subditis non solum non preuident futura, sed nec ordinant presencia; quia non sunt sapiencia illuminati, sed sunt ceci, omni ueritatis lumine destituti. Vnde de eis dicitur Is. $56(56,10)$ : Speculatores eius ceci omnes, canes muti non ualentes latrare. Tales enim non attendunt mala que in ciuitatibus fiunt, quia ceci sunt; nec mala redarguunt, quia muti sunt. Canes enim muti ad nichil utiles sunt, unde nec pane digni sunt, sed a domo repellendi sunt. [...]Sexto, beatus Antonius habuit sapienciam confessorum, siue pocius sanctorum doctorum, que est sicut sapiencia magistrorum. Sapiens enim doctor ille esse dicitur, qui prudenter docet suas scolas; sapiencior ille est, qui docet unam totam prouinciam; sed sapientissimus ille est qui docet omnem terram. Item sapiens doctor est, qui prudenter docet in aliquo tempore, sicut in hyeme tota; sed sapiencior, qui docet in tota uita. Sed sapientissimus, qui sic doceret in ista, ut esset sibi et aliis utile in futura. Talis reuera fuit Antonius, qui primo docuit semetipsum uigilando, orando, ieiunando et carnem seruire spiritui cogendo. Secundo, docuit proximum non tantum in uno loco, sed undique per circuitum, non ea tantum que ualerent in hac uita ad meritum, sed que ualerent in futuro ad premium et ad euadendum infernale supplicium. Et propterea de eo potest exponi quod dicitur Eccli. $2(21,16)$ : Sapientis scientia quasi inundacio habundabit, et consilium eius quasi fons uite permanet. Sed quis hodie est, qui sic proximum doceat, qui sic ei de bono anime consulat, et non pocius uana querere, uana amare, uanis omni tempore deseruire? Statim modo ut nati filii aliquid cognoscere incipiunt, statim instruuntur ut uanis intendant, ut mundanis assuescant, ut computare discant. Quis unquam modo docet filium ut Deo seruiat, ut ad ecclesiam uadat, ut mundum relinquat? Heu me, dolendum et plorandum est ualde, quia pagani olim filios suos et filias tradebant templis demonum quos colebant, et ibidem eos seruire omni tempore statuebant. Sed christiani, serui empticii, Christi precioso sanguine comparati, uolunt filios suos magis seruire mundo quam Christo, magis crudelissimo tyranno quam uero et piissimo Domino. Sunt enim omnes tales lupis similes, qui filios mox adultos docent ad predam et instruunt ad insidias canibus et ouibus faciendas.» cfr. Gamboso (1978, pp. 285; 287). A edição que estou a propor é feita a partir dos manuscritos: El Escorial, Real Biblioteca, P-III-15, ff. 60va-63vb; Padova, Biblioteca Antoniana, ms. 490, f. 79ra - 81ra; Roma, Casanatense, ms. 498, f. 137v - 143r; Vaticano, Vat. Lat. 9884, f. 86v - 90r.

Horizonte, Belo Horizonte, v. 15, n. 48, p. 1274-1298, out./dez. 2017 - ISSN 2175-5841 
afirmações falsas. O que é interessante aqui é o convite peremptório ao pregador incansável para ser o portador da verdade da salvaçãoำ. O conteúdo dos tons, nos três frades, é muito diferente, embora sejam quase contemporâneos e ativos em áreas não muito distantes um do outro. A coragem ostentada por Bindo e Corrado é sempre coroada com um convite para os tons de bondade, a fim de capturar a favor do público e está em conformidade com o uso mais difundido da imagem do santo. O anônimo Chigiano desvia significativamente disso. Apesar da hipótese mais simplista de que esse irmão não era um coração de leão e tentou justificar seu comportamento de modo que talvez custou-lhe algumas reprimendas por uma autoridade desconhecida, para nós, é impressionante. Estamos também a nos perguntar se as causas do presente convite à cautela eram outras. Talvez uma insistência excessiva pelos frades tinha colocado alguém em perigo ou talvez, como parece ecoar suas palavras, ele acredita na manutenção do status quo da cidade, ou seja, não atacar muito certas pessoas ou categorias, como este aparece o sentido final da advertência, poderia ser uma opção melhor ao perigo que levaria uma pregação "muito verdadeira". Em qualquer caso, Santo António, amostra da pregação urbana, torna-se aqui também um exemplo de oportunismo político, ao qual os frades são convidados a cumprir. Talvez, este anônimo não fosse um santo, mas certamente oferece um vislumbre da vida cotidiana que não se encontra em outros textos dedicados ao santo português.

\footnotetext{
${ }^{15}$ «Exemplum de apostolis. Gregorius: implet piscatorem etc. Cuius doctrina est eciam utilis quia uiam salutis predicat et denuntiat. Doctor est cui ueritas ipsa perhibet testimonium dicens: Cum autem uenerit spiritus ueritatis uos docebit ueritatem omnia, uidetur lo XVI $(16,13)$. Omnis enim perfecta ueritas consistit in tribus scilicet: in promissione, communicatione et assercione. Adueniens ergo spiritus sanctus docet ueritatem promissionum, ueritatem communicationum, ueritatem assercionum. Mundus habet falsas promissiones, caro falsas communicaciones, superbia uite habet falsa iudicia et falsas asserciones. Mundus promittit felicitatem quia homo ad peccatum trahitur, caro comminatur inportabilitatem penalitatum qua homo a bono quique retrahitur. Superbia asserit se nulla pena dignam uel de facili ueniam habituram, ut sit malo in ora longior protrahatur. ludicat enim superbia quod quique aliis est superior propter hoc aliis sit melior et magis debeat honorari, ut falsa assercio euidenter ostenditur, sed omnia ista uincit ueritas que habet ueras promissiones, ueras communicaciones, ueras asserciones. Ideo II Esdre IV () dicitur quod magna est ueritas et forcior pre omnibus, Omnis enim terra ueritatem inuocat, id est homines uiatores ipsas inuocant orando propter promissiones implendas. Celum etiam ipsam benedicit. id est beati in patria ipsam benedicunt propter promissiones impletas et omnia opera et bona moue[222ra]tur.» Padova, Biblioteca Antoniana, ms. 450, ff. 220ra-222ra: 222ra. Inuocaui et uenit in me spiritus sapientie [Sap. 7, 7]. Spiritus sanctus interpres est omnium eloquiorum, doctor omnium uerborum, suggestor omnium bonorum. Ideo innotandus est ut sit nobis interpres ad loquendum, lux ad intelligendum, uirtus ad operandum [Expl.] communicaciones et non est in ea quicquam inquiriri, propter ueras asserciones et hoc est omnes et perfecta ueritas. Veniens ergo spiritus ueritatis docebit omnem hius ueritatem communicens omnem falsitatem. Rogemus etc.
} 
Outro breve exemplo da centralidade do ambiente urbano na pregação italiana sobre o santo é oferecido pelo segundo sermão de sancto Antonio no manuscrito 76 da Biblioteca Municipal de Todi ${ }^{16}$. Aqui, a referência ao santo é limitada ao início onde o leitor é informado de que ele foi um exemplo do ensino ditado para o thema (Glorietur frater humilis in exaltatione sua. Iac. 1, 9). A pregação do santo não é, portanto, lembrada, pelo menos explicitamente, mas os frades são convidados a ter em mente o seu exemplo durante sua pregação. Têm de ajustar-se a ele que resgatou os fracos e os doentes, instruiu os ignorantes, admoestou os pregadores e os injustos ${ }^{17}$. Apenas sobre o último ponto, o autor franciscano do sermão revela uma injustiça sofrida pelos frades, no ano anterior, dos poderosos da cidade, relativa a falta de provisão, como resultado de uma absolvição não especificada. Com uma mudança do destinatário, o autor dilui sua amargura numa advertência a seus confrades, para que não repita-se o erro e tenham o cuidado do bem comum da cidade, que é confiada a eles mesmos ${ }^{18}$. Embora António aqui apareça menos do que em outros textos, a posição da referência significa que ele é como um exemplo de pregador cívico justo e eficaz, ao contrário do que foi feito pelos frades com a falta da provisão no ano anterior.

Para uma primeira conclusão, a cidade é, para os autores destes ciclos homiléticos, um campo de ação em que o santo é um teste de sua virtude, que é a

\footnotetext{
${ }^{16}$ Todi, Biblioteca Comunale, 112 (ms. 76), cc. 200va-201rb (138va-139rb). «lac. 1b (1, 9): Glorietur frater humilis in exaltatione sua. Sapientum discretio et hominum ditari uolentium in duobus precipue consistit, scilicet ut sapienter lucrari studeant. Vnum enim sine reliquo aut non prodest aut impossibile est [Expl.] . Attendite comune bonum ciuitatis quia omnes comune bonum semper nostram ciuitatem in bono statu seruabitis. Quid enim a<n>tiquitus exaltauero manos nisi qui comune bonum amabant et proprium lucrum comuni non preferebant.»

${ }^{17}$ "Iste autem sanctus amore et dilectione fuit plenus. Ad lucrandum et humilitate ad conseruandum. Circa amorem nota quod beatus Antonius suum amorem ad lucrum exposu<i>t. Circa debiles et infirmos ipsos caritatiue adiuando. Circa ignorantes et inscios ipsos instruendo. Circa peccatores et iniquos ipsos arguendo. Lucratus est enim amicabiliter, sicut nutrix debilium, sicut docto simplicium, sicut iudex peccantium.» Todi, Biblioteca Comunale, 112 (ms 76, c. 201rb (139rb)

${ }_{18}$ «Vnde cum anno primo uoluntatis fuerit communi istius hominibus gratiam facere et nobis reliquia de ipsis mortale ablatis alliqatenus prouidere aliqui tamen ex pigritia remanserunt, nolentes satisffacere infra tempore quo paruos potuerunt absolui. Vnde magis curantes de eorum animabus quam de nostra prouisione cum in quo danda periculo constituti contineatur quod si consilio placet per nos religiosos possint istius modi homines absolui et aliquid quod reciperemus ab eis possimus mutilate fratrum conuertere uoluntatem nostram et assensum super predicto capitulo et absolutione requiro ut anime obligate possunt absolui et fratribus possit aliquatenus prouideri quod quidem actenus parum fuit et in posterum sicut extimo minus erit. Non autem reputo minimum dummodo Deo satisfiat de absolutione animarum. In hiis autem et aliis omnibus salutem nostram et communis ulitatem nos altissimus faciat operari. Nos autem si animas poterimus liberare, quod beneficium nobis promissum recipiamus certi sumus. Erimus enim solum quale quale membrum Dei, sed membrum pretiosum, scilicet os eius, sicut promittit et tangit per predictum uerbum.» Todi, Biblioteca Comunale, 112 (ms 76, c. 201rb (139rb)
} 
sabedoria entendida como pregação. António está agindo como um pregador e, portanto, é um modelo perfeito para todos os outros pregadores que estão a agir num contexto idealmente igual ao seu. Para alcançar este propósito, ou seja, um desejo de imitar o santo no seu melhor, a lembrança dos locais exatos onde manifestou o seu dever pastoral não só não era útil mas talvez pudesse tornar-se contraproducente. Nesse sentido, a ausência de referências a Pádua, parece ditada pelo desejo de universalizar a pregação de António, como se fosse aplicável em qualquer ambiente urbano.

Certamente, uma prova em contrário é dada pelos sermões raros que fazem referência explícita à pregação de António em Pádua, ou pelo menos à cidade no rio Brenta sendo relacionada ao santo, talvez lembrando-se que o António também é o patrono da mesma. São muito poucos, pelo menos para o período anteriores a 1350, e podem ser atribuídos a autores ativos no bairro da cidade do Brenta. No sermão veneziano Mutabo habitum et sic ad pugnam vadam, bem como naqueles de Lucas Lector e de Servasanto de Faentia, a memória paduana de António tem como objetivo de ligar a veneração franciscana com a cívica, talvez relacionada com a peregrinação ao túmulo e ao culto das relíquias do santo (GAMBOSO, 1969, p.243; LOMBARDO, 2012, p. 21-22).

A referência à cidade de Pádua, no entanto, pode desempenhar um papel mais vinculativo e servir para distinguir o bom exemplo do santo dos seus confrades. Assim, o autor anônimo do sermão curto, contido num manuscrito tudertino (Ms. 126 cc 36rb-36va), limita a ação de António à cidade de Pádua e abre o texto com as palavras: Paduanorum apostolus beatus Antonius in huius verbi serie commendatur quadrifarie e constrói o seu próprio texto, sem qualquer referência a uma possível imitabilidade do santo ${ }^{19}$. Era um apóstolo para os paduanos, falou

\footnotetext{
19 «Paduanorum apostolus beatus Antonius in huius uerbi serie commendatur quadrifarie, uidelicet: a feruore dilectionis, splendore cognitionis; uirore operationis; ualore predicationis.Qua substinuit grauia sine defectione, cognouit subtilia sine deceptione, operatus est ardua sine remissione, predicauit utilia sine primarum acceptione uel commendatur ut feruentissimus amator sine defectione, perspicacissimus cognitor sine deceptione, uirtuosissimus operator sine remissione utilissimus predicator sine primarum acceptione.» Todi, Biblioteca Comunale L. Leonii, ms. 126, c. 36rb.
} 
igualmente aos grandes e aos pequenos e, como tal, deve ser reverenciado ${ }^{20}$. O leitor não poderá identificar-se com o santo, só conhecer os dados essenciais úteis para o culto.

A menção aos "paduani”, no sermão com thema Argentum electum lingua iusti (Prv. 10, 20), afasta ao longo do tempo o exemplo de António e torna-o numa contrapartida com a qual condena os pregadores da sua época. Separa claramente o santo de seus sucessores no officium praedicationis. António em Pádua agiu com uma língua de prata, isto é, com voz justa e casta, foi capaz de infundir terror em pecadores, lhes lançou no rosto os vícios e ameaçou com a punição eterna aos seus ouvintes para ensinar a verdade da palavra de Cristo. Os pregadores do tempo do escritor são falsi testes, detractores, seminatores discordiarum, que é tão distante do exemplo da "lingua placabilis lignum vite ", que o santo provou ser na sua campanha de pregação de $1231^{21}$.

\section{O final da Idade Media: António, o santo de Pádua}

Depois de 1350, a relação entre Pádua e António é mais presente na pregação e na arte. A cidade de Pádua, onde o exíto da santidade do pregador franciscano tornou-se evidente, ganhou nesta altura um papel central na identificação misma do

\footnotetext{
${ }^{20}$ «Vnde dicitur in ystoria sua: «Loquens magnis paruulis ueritatis iaculis eque feriebat». Dicit ergo: Repletus sum etc. Circa quod sciendum quod repleuerunt beatum Antonium fortitudine. Replent fortitudine consideratio eternalis premii» Todi, Biblioteca Comunale L. Leonii, ms. 126, c. 36rb.

${ }^{21}$ " Beatus Antonius amabilis demonstratur: propter uitam, unde iustus dicitur; et propter doctrinam, ideo eius lingua dicitur esse sicut argentum electum [...] Et quia talis ac tante extitit sanctitatis uite, merito potuit exercere predicationis officium. Vnde dicitur quod lingua huius iusticie fuit argentum electum. Ideo notandum quod Lingua beati Antonii triplicem recepit similitudinem, scilicet: argenti, calami et ligni uite. Argenti, quantum ad terrorem quem incuciebat peccatoribus Argentum enim est ualde sonorum, et ipse beatus Antonius triplicem dedit sonum [...] Ideo dicit lob XXVIII $(28,1)$ : Habet argentum uenarum suarum principia: calami, quantum ad morum informationem. Vnde Ps. $(44,2)$ : Lingua mea calamus scribe uelociter scribentis. Ideo beatus Antonius potuit dicere paduanis II Cor. III (3, 3): Epistola estis Christi, ministrata a nobis, et scripta non atramento, sed Spiritu Dei uiui. Sic scribebat iste Sanctus quando docebat fidem, spem et caritatem et ceteras uirtutes. Sed heu!, multi hodie linguas suas quasi calamos diaboli posuerunt: sicut falsi testes, de quibus dicit Is. X $(10,1)$ : Ve qui condunt leges iniquas, et scribentes iniusticiam scripserunt. Talem calamum exhibuit linguam suam uxor Achab, que scripsit litteras contra Naboth ut lapidaretur, ut dicitur II Reg. XXI (21, 8); sicut detractores, de quibus dicit Ps. (139, 4): Acuerunt linguas suas sicut serpentis. Ideo dicit Eccli. XXVIII $(28,23)$. Beatus qui tectus est a lingua nequam; sicut seminatores discordiarum. Vnde Eccli XXVIII $(28,15)$ : Susurro et bilinguis maledictus, multos enim turbauit pacem habentes. Non talis fuit calamus beati Antonii, sed calamus Christi fuit ad salutem peccatorum.» Vaticano, Biblioteca Apostolica Vaticana, Latini, ms. 6005, ff. 100ra - 100va; Arras, Bibliothéque Municipale, ms. 204 (335), ff. 204ra-204va; Assisi, Biblioteca del Sacro Convento, ms. 432, ff. 67va-67vb; Padova, Biblioteca Antoniana, ms. 470, ff. 134rb-135ra. cfr. Gamboso (1970, p. 283-285).
} 
santo, obscurecendo definitivamente no imaginario coletivo outros centros como Limoges, ou ofuscando talvez a sua origem lisboeta. É um pouco difícil entender se essa relação foi geral ou não, dada a dificuldade de encontrar sermões do período, mas alguns dos sermões parecem concordar com uma historiografia que, muitas vezes sem trazer evidência textual, sempre afirmou que a ligação entre a cidade e o santo foi reforçada nesse período (LOMBARDO, 2014). Os sermões são, de fato, poucos. As razões podem ser variadas. Em primeiro lugar, as dificuldades para o estudioso analisar os textos devido à falta dum instrumento igual ao Repertorium de Johannes Baptist Schneyer para o último século e meio da Idade Média. Em segundo lugar, um desbaste efetivo da pregação do Santo por causa da tendência para sobreposição com a festa de Corpus Domini nos calendários litúrgicos. A festa foi introduzida em 1264, mas explodiu apenas a partir do final do século XIV e muitas vezes levou à omissão do sermão de Santo António. Não quero dizer que o santo não seria venerado. Ao contrário, neste momento, há um florescimento da iconografia e da narrativa que sublinham o respeito milagroso (DE MANDACH, 1899, p. 169-249; BERTAZZO, 1995; BORGIGNON, 1995). Mesmo os frades compositores de sermões que omitiram o sermão sobre o Santo, às vezes, queriam honra-lo através da inserção de um breve olhar no texto para o Corpus Domini.

Dada a escassez de fontes a que temos acesso provaram particular interesse as pistas que podemos tirar deles ${ }^{22}$.

Não vamos falar de uma evolução, porque muitos entre os textos sobre santo António permanecem na interpretação tradicional do santo. Entre esses, Iohannes Contractus, um frade franciscano morto em 1383, cuja origem é muito debatida (há estudiosos que pendem que era da Hollanda e outros que acreditam que era da Alemanha do Sul ou que também nunca existiu). Em qualquer caso, a sua obra fica atestada em inúmeros manuscritos e teve fortuna imensa até ao início da Idade

\footnotetext{
22 Omito aqui, para brevidade, as refêrencias ao longo sermão de Roberto Caracciolo, no qual não só o pregador lembra o papel de António de Pádua como patrono, mas também reivindica uma relação especial com o santo, do qual afirma ser conhecedor e devoto. Falei deste assunto numa jornada de estudo organizada em Pádua no 10 dezembro 2014 entitulada "Acqua, pane, devozione. Sant'Antonio fra l'Antico e il Contemporaneo".
} 
Moderna (AUBERT, p. 199; AUBERT, 2000, p. 1999; MOSSMAN, 2012, p. 256 259). No seu sermão de sancto Antonio, o santo é apresentado de maneira tradicional: é um santo imitável por quatro causas: a fervore contemplationis, ab excellentia predicationis, ab efficacia meritorie operationis, a perseverancia sancte consummationis, e falta qualquer referência geográfica aos milagres 23.

O mesmo acontece num sermão franciscano da primeira metade do século XV, conservado na Biblioteca Vaticana (Archivio di San Pietro, D213) 24. Aí, o santo é exaltado por sua vida e sua sabedoria é amostra de pobreza, de conformidade à Regra, de vilitas, e modéstia. Na verdade, nestes dois casos é visível uma lacuna entre o modelo - António e o público: os pregadores, enquanto exaltam as mesmas características do santo dos seus antecessores, não convidam mais explicitamente o ouvinte / leitor a imitá-lo. A história é plana e até mesmo as lamentações sobre a perda de valores antigos é uma coisa do passado e não termina com uma chamada ao exemplo de António.

A mudança de mentalidade está mais evidente em alguns sermões da Observância. Parece que foram apenas estes frades, como já foi sugerido por outros antes de mim, a dar o impulso à devoção mais popular ao santo Português [GAMBOSO, 1977, p. 90; BUIJSEN, 1989, p. 4; BERTAZZO, 1995, p. 20). As primeiras atestações iconográficas do Santo António com o menino Jesus (Liber Miraculorum, ...) são do século XV (BINOTTO, 1995, p. 9), assim como a maioria das imagens dos milagres. (SEMENZATO, 1985, tabulas; DE MANDACH, 1899, p. 195-327)]. Cúmplice desta mudança, era uma nova atitude em relação a António, cuja função de pregador exemplar parece ser ajustada com a chegada de novos modelos, o primeiro de Bernardino de Siena, e procede-se uma transformação

\footnotetext{
${ }^{23}$ O sermão como tema está erroneamente incluído no Repertorium de Schneyer (SCHNEYER, 1969 - 1974 :vol. 3, p. 441), ao número 110 : Iustum deduxit Dominus (Sap. 10,10) In verbis istis commendatur beatus Antonius, scilicet per affectionem religionis... Ad hanc hodie pervenit beatus Antonius, cuius meritis ad eandem nos perducat. Encontrei o sermão nos manuscritos seguintes: Munich, Bayerische Staatsbibliothek, mss : Clm 566 ff. 71rb-77va; clm 28471, pp. 136vb-138ra; clm 7427 ff. 127ra-128rb; clm 7450. ff. 107r108r ; Clm 16442, cc. 104rb-105vb ; Clm 16014, ff. 80rb-81rb ; Uppsala, University Library, ms. 402, ff. 13v-16r ; Uppsala, University Library, ms. 405, ff. 93rb-95vb.

${ }^{24}$ BAV, Archivio del Capitolo di San Pietro, ms. D.213, coll. 207-208: Perfectus omnis erit sicut magister eius [Lc. ]. Beatum Antonium duo commendabilem reddunt. Primum est opus uirtuosa, quod notatur cum dicitur: perfectus autem omnis erit. [Expl.] Et sicut enim secutus in conuersatione, sic [...] secutus est ipsum in glorificatione, ad quam nos perducat. Amen.
} 
estrutural profunda do sermão que é bem conhecida na sequência das gerações de irmãos.

No sermão preservado no manuscrito Vaticano Latino 4258, com thema baseado no livro do Eclesiático 50, 6 (Quasi stella mattutina in medio nebule etc.) a ligação entre António e a Ordem dos Frades Menores é agora um dado adquirido. Prefere-se explicar desde o título principal e, em seguida, em outros menores, que o santo do dia é Santo António de Pádua confessor mirífico ${ }^{25}$. Neste sermão o tom volta a ser muito semelhante ao da Assidua. Se o hagiógrafo havia quase obscurecido a presença dos frades na cidade de Pádua, o pregador do século XV é totalmente silencioso da Ordem e restaura a centralidade da relação pessoal entre o Santo e os lugares da sua ação. O sermão é apresentado dividido em três secções principais, cada uma correspondendo às três estrelas às quais António é comparado com base nas Escrituras litúrgicas ${ }^{26}$. Cada uma é subdividida em três “privilégios” que António teria adquirido durante a sua vida. A pregação aqui é equivalente ao primeiro privilégio do sol, ou seja, ao conhecimento que permitiu-lhe refutar o erro e educar ao bem. Os episódios têm um impacto altamente visual. Evoca-se aqui o milagre da conversão do herege Bononillo (chamado Bonillo) e a pregação em Pádua, embora com o objetivo de introduzir a concessão do dom da profecia ${ }^{27}$. Em comparação com os sermões da primeira parte desta investigação, aqui, a história do impacto que as palavras tiveram na cidadania é perdida geralmente a favor dos episódios miraculosos, como a pregação aos peixes, a conversão do herege e o reconhecimento do Cristo pelo asno. A mudança de tom, talvez, é mais próxima aos gostos dos pregadores do século XV (SOLVI, 2013, pp. 165 - 166; DELCORNO, 1980, p. 86 -

\footnotetext{
25 « Hec uerba scribuntur in hoc die nostra santa mater ecclesia fideles suos inuitat ad gloriam mirifici confessoris Antonii de Padua qui mistice comparatur stelle, lune et soli, quia celum uiris iustis, terram peccatoribus assignatur, iuxta illud Is. 76: Celum meum sedes est, terram autem scabellum pedum pedum meorum.» Vaticano, BAV, Vat. Lat. 4258, ff. 48va-49rb.

${ }^{26}$ «Pars prima sermonis: de tribus privilegiis beati Antonii de Padua stelle simili [...]Pars secunda sermonis: de tribus sequentibus privilegiis beati Antonii lumine comparato [...] Pars tercia sermonis: de tribus vltimis privilegiis beati Antonii de Padua. Tribus aliis priuilegiis similatur beatus Antonius soli fulgenti, quia secundum beatum Augustinum sol est, lucet et calet.» Vaticano, BAV, Vat. Lat. 4258, ff. 48va-49rb.

${ }^{27}$ « Primum patet ex mundi contemptione, secundum patet ex habitus et religionis mutacione, tertium patet ex heresis et maxime apud Ariminum extirpacione. Vicit enim heresiarcham Bonillum cum sacramento altaris. Quartum patet ex feruenti predicatione precipue Padue predicando unde legitur: propellebat eum spiritus quodam futurorum presagiorum diuinarum studia litterarum in quibus iugiter meditando non solum in agro alieno uitia extirpando uirtutes insereret, semetipsum sollicitus primitus excolendo cognouit.» Vaticano, BAV, Vat. Lat. 4258, ff. 48va-49rb.
} 
90), mas testemunha a mudança da própria percepção da relação entre António e os fiéis. No estudo dos sermões do final da Idade Média, para o Santo, é necessário salientar que os textos tiveram um valor pastoral mais pronunciado e um caráter que é, de certa forma, mais popularizado do que os do período anterior. Também, têm frequentemente um resumo da vida do santo e uma preferência marcada para o gosto de episódios milagrosos [A vida de referência nesta altura é quase sempre a Chronica XXIV Generalium (cfr. DOLSO, 2004) O testemunho da inserção de quase toda a vida de António num sermão é oferecido mesmo pelos sermões de Roberto Caracciolo (cfr ROBERTUS CARACCIOLUS, 1489, cc. 191va-194vb) que pelo texto de João Capistrano (Cfr. Capistrano, Biblioteca dell'Ordine dei Frati Minori, ms. 30, ff. $130 r-132 v$ e ms. 31, ff. 141r - 143v) entre os outros]. Renova-se, nesta altura, um gosto mais forte para o milagroso e a pregação sobre o santo não é exceção.

Pelbarto de Temesvar, por exemplo, no seu longo sermão para Santo António dedica metade do espaço da exposição a vida de António, com preferência para milagres. O frade, nascido por volta de 1430, nativo da Hungria, educado em Cracóvia e depois leitor, pregador e escritor, no convento de Santo João, em Buda até sua morte, que ocorreu em 1504, escreveu coleções de sermões que tiveram sucesso considerável, especialmente em Europa Central e Oriental. Portanto, podese supor que o seu texto sobre o St. António teve um bom impacto no imaginário popular.

O seu texto se abre com uma reflexão muito doutrinal e teórica sobre a pregação boa e fecunda, mais adequada para a meditação por um leitor médio ou estudioso, no entanto, com um bom conhecimento de teologia. Segue uma segunda parte, mais anedótica, que resume-se literalmente na vida do santo, com um gosto especial para os episódios miraculosos, ente os quais o milagre do herege Bononillo, a tentativa de asfixia por parte do diabo e a visão na morte, já presentes em alguns sermões do século XIII, estão ao lado da pregação aos peixes e a história do asno, 
por vezes ausentes naqueles ${ }^{28}$.

\section{Conclusão}

Para concluir este panorama, a relação entre António e a cidade, ideal ou real, como Pádua, desempenha um papel talvez não central, mas pelo menos importante para os frades medievais. Os que decidiram largar as ações de António dentro dum contexto como a cidade, agiram para fins diferenciados, mas todos tinham o objetivo de apontar o exemplo positivo do santo pregador numa civitas ainda vista como corrupta e cheia de pecado, ou mesmo enganosa. Até a Observância, quase nunca, esse era o lugar onde os milagres do santo aconteceram, mas era um ótimo lugar onde o santo era capaz de expressar o seu carisma, agindo para o bem comum e para a salvação de almas. Aí afetou os destinos da comunidade e dos indivíduos. Conforme ao seu exemplo, cada pregador deve finalmente ser um novo António nas ruas e no púlpito e assim ganhar o seu canto de santidade. O papel de Pádua está diferente. O apelo à cidade foi retirado rapidamente nos sermões medievais e tem um novo sucesso apenas no final do período em análise.

No final da Idade Média, santo António acabou de ser, em certa medida, o modelo para os frades, talvez atraídos pelos santos agora mais próximos no tempo. Esta perda de eficácia do santo, no nível mais sábio, decretou o seu sucesso no nível popular, de que ainda goza, graças à pregação de seus milagres. Os novos argumentos, acompanhados por um florescimento da iconografia sem precedentes,

\footnotetext{
${ }^{28}$ " Aliud quoque miraculum, dum praedicaret Ariminiae sanctus Antonius, tunc aderat quidam haereticus, qui non sane sentiens de corpore Christi in contemptu illius, hostias non consecratas saepius asino suo praebebat in cibum, quem cum Antonius persuaderet in fide veritatis, et ille recusaret, convenit cum eo, ut de hoc experientia fieret sic, quod per dies tres asinus suus praedictus sine cibo transiret, et die tertia in foro celebrata missa ab Antonio reservatoque sacramento illud inter hostias non consecratas reponeret, atque hoc modo asinus famelicus invitaretur ad pabulum. Quod cum factum fuisset coram multitudine maxima, animal illud appropinquans sportae, in qua corpus Christi inter hostias non consecratas reverenter erat reconditum, ecce divino miraculo cognovit Dominum suum, et caput et pedes inclinans humiliter adoravit, neque curavit de cibo, quo indigebat. Cumque verberibus ab haeretico angeretur et traheretur et volveretur, semper faciebat adorando, ut prius, ob quod haeretici ad fidem redierunt, et Antonius gratias Deo egit. Item aliud miraculum, quod dum multi haeretici Antonio in quadam civitate detraherent, et populum a praedicatione averterent, beatus Antonius ad litus inibi maris accedens praecepit pisces convenire, et ecce per turmas venientes audierunt eum praedicantem, nec eorum maiores impediebant, ut solent, minores, et tandem benedicens eis abierunt, aspicientibus haec cunctis et mirantibus.» http://sermones.elte.hu/pelbart/index.php?file=pa/pa009.
} 
valeu-lhe a reputação de santo dos milagres, nome pelo qual é conhecido hoje em todo o mundo.

\section{REFERÊNCIAS}

ACCROCCA, Felice. Da pater Padue a malleus hereticorum. Gregorio IX e il caso di Antonio di Padova. In: ROSSI, Margherita Maria - ROSSI, Teodora (eds.), Cause di canonizzazione di alcuni maestri medievali. In ricordo di Padre Louis-Jacques Bataillon, OP. Roma: Angelicum University Press, 2009, pp. 291-311. Agora in: ACCROCCA, Felice. L’identità complessa. Percorsi francescani fra Due e Trecento. Padova: centro Studi Antoniani, 2014, p. 67-84.

AUBERT, Roger. Jean Kortz. In: Dictionnaire d'Histoire Religieuse et de Géographie Ecclésiastique, t. 27: Jean E... - Jonnart, Paris: Letouzey et Ané, 2000, p. 199.

AVEZOU, Robert. Un prince aragonais archevêque de Tolède au XIV siècle. D. Juan de Aragón y Anjou. In: Bulletin Hispanique, 32, nº. 4, 1930, pp. 326-371.

BALDUINUS AB AMSTERDAM, 1958 = BALDUINUS AB AMSTERDAM, Tres sermones inediti Joannis de Rupella in honorem S. Antonii Patavini. In: Collectanea

Franciscana, 28, 1958, p. 33-58.

BERTAZZO 1995 = BERTAZZO, Luciano. Note di iconografia antoniana. In: Antonio ritrovato: il culto del Santo tra collezionismo religioso e privato. Padova: Il Poligrafo, 1995, p. 19-25.

BINOTTO, Margaret (ed.). Ritratti per un santo. Padova: Centro Studi Antoniani, 1995.

BORGIGnON, Celso. A iconografia de santo Antonio de Pádua, in: Cadernos da ESTEF, n. $14,1995 / 1$, p. 19-29.

BOUGEROL, Jacques-Guy. Saint François dans les premiers sermons universitaires. In: GIEBEN, Servus (coord.). Francesco d'Assisi nella storia. Secoli XIII-XV. Atti del primo Convegno di studi per l'VIII centenario della nascita di S. Francesco 1182-1982 (29 settembre - 2 ottobre 1981, Roma: Istituto Storico dei Cappuccini, 1983, p. 173-199.

BUIJSEN, Edwin. The iconography of St. Anthony of Padua in Flemish Art up to the counter-reformation. In: Il Santo, 29. 1989, p. 3-28.

CAROZZI, Claude. Jean Rigauld biographe de saint Antoine. In: BERTAZZO, Luciano (ed.). «Vite» e vita di Antonio di Padova: Atti del Convegno internazionale sulla agiografia antoniana (Padova 29 maggio - 1 giugno 1995). Padova: Centro Studi Antoniani, 1997, p. 71-88. 
DE MANDACH, Conrad. Saint Antoine de Padoue et l'art italien. Paris: Librairie Renouard - Henri Laurens Editeur, 1899.

DELCORNO, Carlo. Il racconto agiografico nella predicazione dei secoli XIII - XV. In: Agiografia nell'Occidente cristiano. Secoli XIII - XV. Roma: Accademia Nazionale dei Lincei, 1980, p. $79-114$.

DELMAS, Sophie. «Entre l'église et l'état». Les vertus disputées de Louis d'Anjou prince, franciscain et evêque. In: LOMBARDO, Eleonora (ed.), Models of Virtues. The Role of Virtues in Sermons and Hagiographyfor New Saints' Cult( $13^{\text {th }}$ to $15^{\text {th }}$ Century). Padova: Centro Studi Antoniani, 2015, p. 137-149.

DOLSO, Maria Teresa (ed.). Vita di sant'Antonio confessore ovvero vita seconda o legenda anonima o giuliana. Autore Giuliano da Spira dell'Ordine dei Minori (c. 1235). In: DOLSO, Maria Teresa (coord.). Fonti agiografiche dell'Ordine francescano. Padova: Efr Editrici francescane, 2014, p. 295-323.

DOLSO, Maria Teresa. La Chronica XXIV Generalium. Il difficile percorso dell'unità nella storia francescana. Padova: Centro Studi Antoniani, 2003.

GAMBOSO, Vergilio (ed.). Vita Prima o «Assidua». Padova: Ed. Messaggero, 1981.

GAMBOSO, Vergilio. Cinque sermoni inediti di fra Luca Lettore (c. 1287) in lode di sant'Antonio. In: Il Santo, 9, 1969, p. 233 - 281.

GAMBOSO, Vergilio. Dal s. Antonio storico al s. Antonio della pietà popolare. In: S. Antonio di Padova fra storia e pietà. Colloquio interdisciplinare su "il fenomeno antoniano". Padova: Edizioni Messaggero, 1977, p. 81-109.

GAMBOSO, Vergilio. I Sermoni festivi di Servasanto da Faenza nel cod. 490 dell'Antoniana. In: Il Santo, 13, 1973, p. 3-88.

GAMBOSO, Vergilio. I tre panegirici antoniani di Corrado di Sassonia (m. 1279) e altri sette di autori sconosciuti. In: Il Santo, 14, 1974, p. $63-120$.

GAMBOSO, Vergilio. Introduzione. In: GAMBOSO, Vergilio (ed.). Vita Prima o «Assidua». Padova: Ed. Messaggero, 1981, p. 7-265.

GAMBOSO, Vergilio. Introduzione. In: GAMBOSO, Vergilio (ed.). Vite "Raymundina" e “Rigaldina”. Padova: Edizioni Messaggero, 1992, p. 333-500.

GAMBOSO, Vergilio. Introduzione. In: GIULIANO DA SPIRA. Officio Ritmico e Vita Secunda. a cura di GAMBOSO, Vergilio. Padova: Edizioni Messaggero, 1985, p. 11- 163.

GASPAROTTO, Cesira. La grande missione antoniana a Padova nella quaresima 1231. In: il Santo, 22, 1964, p. 127-152. 
GIULIANO DA SPIRA. Officio Ritmico e Vita Secunda. a cura di GAMBOSO, Vergilio. Padova: Edizioni Messaggero, 1985.

GLORIA, Andrea (ed.). Statuti del comune di Padova dal secolo XII all'anno 1285. Padova: 1873.

HOROWSKI, Aleksander. Repertorium sermonum latinorum medii aevi ad laudem sancti Francisci Assisiensisis. Roma: Istituto Storico dei Cappuccini, 2013.

LAMBERT, Élie. Aragon y Anjou (Juan de). In: Dictionnaire d'Histoire Religieuse et de géographie ecclésiastiques, t. 3: Anforaria-Arfons, Paris: Letouzey et Ané, 1924, coll. 1408-1414.

LOMBARDO, 2012 = LOMBARDO, Eleonora. I «Sermones de sancto Antonio» fra XIII e XIV secolo. Status quaestionis ed edizione del sermone Venezia, Lat. Z. 158 (1779), ff. 120v-122v. In Il Santo, 52. 2012, p. 9-44.

LOMBARDO, Eleonora. Multipliciter commendatur beatus Antonius. Sant'Antonio di Padova come modello di virtù per i frati minori (ca. 1232 - 1350). In: LOMBARDO, Eleonora (ed.), Models of Virtues. The Role of Virtues in Sermons and Hagiographyfor New Saints' Cult (13 ${ }^{\text {th }}$ to $15^{\text {th }}$ Century). Padova: Centro Studi Antoniani, 2016, p. 47-73.

LOMBARDO, Eleonora. The Development of Devotion to Saint Anthony Between Localism and Universalism. In:KUZMOVÁ, Stanislava - MARINKOVIĆ, Ana - VEDRIŠ, Trpimir (coord.). Cuius Patrocinio Tota Gaudet Regio. Saints' Cults and the Dynamics of Regional Cohesion. Zagreb: Hagiotheca, 2014, p. 231-252.

MERLO, Grado Giovanni. A proposito di Fonti agiografiche dell'Ordine francescano. In: Franciscana, 16, 2014, p. 241-252.

MOSSMAN, Stephen. Preaching on St. Francis in Medieval Germany. In: JOHNSON, Timothy (ed.). Franciscans and Preaching. Every Miracle from the Beginning of the World Came about through Words. Leiden - Boston: Brill, 2012, p. 231-272.

PACIOCCO, Roberto. «Nondum post mortem beati Antonii annus effluxerat». La santità romano-apostolica di Antonio e l'esemplarità di Padova nel contesto dei coevi processi di canonizzazione. In: BERTAZZO, Luciano (ed.). «Vite» e vita di Antonio di Padova: Atti del Convegno internazionale sulla agiografia antoniana (Padova 29 maggio - 1 giugno 1995). Padova: Centro Studi Antoniani, 1997, p. 109-135.

PACIOCCO, Roberto. Canonizzazioni e culto dei santi nella christianitas (1198 1302). Assisi: Edizioni Porziuncola, 2006.

PACIOCCO, Roberto. Da Francesco ai «Catalogi sanctorum». Livelli istituzionali e immagini agiografiche nell'Ordine francescano (secoli XIII-XIV). Assisi: Ed. Porziuncola, 1990. 
PELBARTO DE TEMESVAR, Sermones Pomerii de sanctis, Pars Aestivalis:

Disponível em: <http://sermones.elte.hu/pelbart/index.php>. Acesso em: 26 dez 2017.

RIGON, Antonio. Dal Libro alla folla. Antonio di Padova e il francescanesimo medioevale. Roma: Viella, 2002.

ROBERTUS CARACCIOLUS, Sermones de laudibus Sanctorum. Venice: J. Rubeus, 1489. Disponível em: <http://bdh-rd.bne.es/viewer.vm?id=0000097203\&page=1>. Acesso em: 26 dez. 2017.

SCHNEYER, Johann Baptist. Repertorium der Lateinischen Sermones des Mittelalters für die Zeit von 1150 - 1350. Münster im W.: Aschendorffsche Verlagsbuchhandlung, $1969-1990$.

SEMENZATO, Camillo (ed.), Sant'Antonio in settecentocinquant'anni di storia dell'arte. Padova: Edizioni Messaggero, 1985.

SOLVI, Daniele. Il culto dei santi nella proposta socio-religiosa dell'Osservanza. In: I frati osservanti e la società in Italia nel secolo XV. Atti del XL Convegno internazionale (Assisi - Perugia, 11 -13 ottobre 2012). Spoleto: Centro Italiano di Studi sull'Alto Medioevo, 2013, p. 135-167.

STANISLAO DA CAMPAGNOLA. L'angelo del sesto sigillo e l'alter Christus. Genesi e sviluppo di due temi francescani nei secoli XII - XIV. Roma: Laurentianum, 1971.

STRAPPAZZON, Valentino Ireneo (ed.). Vita Prima del beato Antonio detta anche Legenda “Assidua”. In: DOLSO, Maria Teresa (ed.). Fonti agiografiche dell'Ordine francescano. Padova: Efr - Editrici francescane, 2014, p. 237-294.

TILATTI, Andrea. L'«Assidua»: ispirazione francescana e funzionalità patavina. In: BERTAZZO, Luciano (ed.). «Vite» e vita di Antonio di Padova: Atti del Convegno internazionale sulla agiografia.

VILLAPADIERNA, Ignatio de. La tercera Orden Franciscana de España en el siglo XIV. In: D'ALATRI, Mariano (coord.). I frati penitenti di san Francesco nella società del Due e Trecento. Atti del $2^{\circ}$. Convegno di Studi Francescani (Roma, 12-13-14 ottobre 1976). Roma: Istituto Storico dei Cappuccini, 1977, p. 161-178. 